\title{
Papers
}

\section{Meningitis in infancy in England and Wales: follow up at age 5 years}

\author{
Helen Bedford, John de Louvois, Susan Halket, Catherine Peckham, Rosalinde Hurley, David Harvey
}

\begin{abstract}
Objective To describe important sequelae occurring among a cohort of children aged 5 years who had had meningitis during the first year of life and who had been identified by a prospective national study of meningitis in infancy in England and Wales between 1985 and 1987.

Design Follow up questionnaires asking about the children's health and development were sent to general practitioners and parents of the children and to parents of matched controls. The organism that caused the infection and age at infection were also recorded.

Setting England and Wales.

Participants General practitioners and parents of children who had had meningitis before the age of 1 year and of matched controls.

Main outcome measures The prevalence of health and developmental problems and overall disability among children who had had meningitis compared with controls.

Results Altogether, 1584 of 1717 (92.2\%) children who had had meningitis and 1391 of $1485(93.6 \%)$ controls were successfully followed up. Among children who survived to age 5 years 247 of 1584 $(15.6 \%)$ had a disability; there was a 10 -fold increase in the risk of severe or moderate disability at 5 years of age among children who had had meningitis (relative risk 10.3, 95\% confidence interval 6.7 to 16.0 , $\mathrm{P}<0.001)$. There was considerable variation in the rates of severe or moderate disability in children infected with different organisms.

Conclusion The long term consequences of having meningitis during the first year of life are significant: 32 of $1717(1.8 \%)$ children died within five years. Not only did almost a fifth of children with meningitis have a permanent, severe or moderately severe disability, but subtle deficits were also more prevalent.
\end{abstract}

\section{Introduction}

Children are most likely to get meningitis during their first year. Although it is widely acknowledged that the consequences of meningitis in infancy may be severe, there are few reliable data from large prospective studies that focus on the outcome of infection in infancy. None of these have been based on a national population.
In a meta-analysis of 19 prospective studies of the outcome of bacterial meningitis in 1602 children $^{1}$ and a review of follow up reports of neonatal meningitis ${ }^{2}$ there were wide variations in the rates of adverse sequelae associated with infection by different organisms and also variations within groups of organisms. This variation could be explained partly by methodological factors including the retrospective identification of cases, small numbers of participants, the inclusion of children from a wide range of ages, differing lengths of follow up, differences in the proportion of infections caused by different organisms, and either the lack of a control group or the inclusion of inappropriate controls. Few studies have investigated the full range of sequelae associated with meningitis ${ }^{3}$; most have focused on specific outcomes, notably cognitive function and hearing loss..$^{5-9}$

A prospective study of the incidence of meningitis in infancy in England and Wales was carried out between 1985 and $1987 .{ }^{10}$ In that study 1880 children with meningitis were identified; we present the results of a follow up investigation at 5 years of age of the children who survived the initial illness.

\section{Participants and methods}

This follow up study is based on data from the 1717 children who survived an acute attack of meningitis between 1985 and 1987. With the permission of the notifying paediatrician, each child's general practitioner was contacted to confirm that the child was alive and still registered with the practice. If the child was no longer registered at the same practice, the child's current general practitioner was traced. Information on children who had died was sought from hospital records and death certificates. Approval for the study was obtained from the research ethics committees of the collaborating centres.

Permission was sought from the child's general practitioner to approach the family health services authority for the name of another child on the general practitioner's list to act as a control; controls were matched by sex and age to the index child. For both cases and controls general practitioners were asked to complete a questionnaire detailing any health or developmental problems in the areas of neuromotor development, learning, vision, hearing, speech and language, or behaviour, and to indicate whether the child had a seizure disorder. Parents of children in both

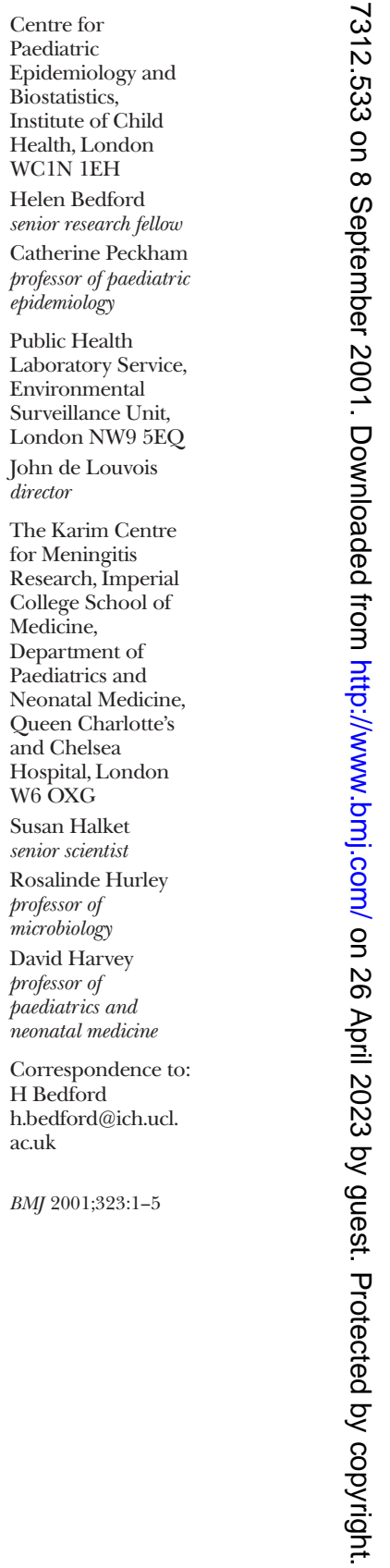


groups also completed a questionnaire about their child's health, development, and schooling. The questionnaires were specially designed for this study and contained both open ended and closed questions. Questionnaires were sent to parents and general practitioners.

Information from general practitioners and parents was combined to provide a complete picture of each child's health. Conditions reported either by the general practitioner or the parent were coded and double entered onto a database. When the evaluation of the severity of a condition differed between the two reports, the more severe condition was included. All information, including the type of schooling, was used to determine the degree of disability.

Children were allocated to one of four categories of disability based on a model developed by McIntyre et al. ${ }^{3}$ Children were classed as having a severe disability if they were unable to attend a mainstream school. This category included children with multiple problems such as severe neuromotor impairment, significant intellectual impairment, severe seizure disorders, and severe visual or auditory impairment.

Children were classed as having a moderate disability if their disability impaired their functioning but was not associated with severe intellectual or developmental impairment. Children in this category attended mainstream schools with or without additional support. This category included children with mild neuromotor disabilities, intellectual impairment, moderate sensorineural hearing loss, mild or moderate visual impairment, epilepsy that was controlled with treatment, and hydrocephalus without complications.

Children were classed as having mild disorders if they had a condition that is prevalent among children of the same age but is not typically associated with meningitis. This category included children with middle ear disease, squint, febrile convulsions, and behavioural problems.

Children were classed as having no disability if there was no evidence of developmental problems, however, conditions such as asthma and eczema were included in this category.

\section{Data analysis}

The prevalence of problems reported in each health and developmental domain, the relative risks, 95\% confidence intervals, and $\mathrm{P}$ values were calculated using SAS and EpiInfo statistical packages. The prevalence of problems was also calculated according to the organism associated with infection and time of onset (neonatal period or later). The proportion of children

Table 1 Number (percentage) of children reported to have health or developmental problems

\begin{tabular}{|c|c|c|c|c|}
\hline & \multicolumn{2}{|c|}{ Group } & \multirow[b]{2}{*}{$\begin{array}{l}\text { Relative risk } \\
(95 \% \mathrm{Cl})\end{array}$} & \multirow[b]{2}{*}{$P$ value } \\
\hline & $\begin{array}{c}\text { Meningitis } \\
(n=1584)\end{array}$ & $\begin{array}{l}\text { Control } \\
(n=1391)\end{array}$ & & \\
\hline Learning difficulties & $118(7.5)$ & $15(1.1)$ & $7.0(4.1$ to 11.8$)$ & $<0.001$ \\
\hline Neuromotor disabilities & $128(8.1)$ & $13(0.9)$ & $8.6(4.9$ to 15.2$)$ & $<0.001$ \\
\hline Seizure disorders & $116(7.3)$ & $37(2.7)$ & 2.7 (1.9 to 3.9$)$ & $<0.001$ \\
\hline Hearing problems & $408(25.8)$ & $190(13.7)$ & 1.9 (1.6 to 2.2$)$ & $<0.001$ \\
\hline Ocular or visual disorders & $217(13.7)$ & $55(3.9)$ & $3.4(2.6$ to 4.6$)$ & $<0.001$ \\
\hline $\begin{array}{l}\text { Speech or language problems, } \\
\text { or both }\end{array}$ & $247(15.6)$ & $64(4.5)$ & 3.5 (2.8 to 4.6$)$ & $<0.001$ \\
\hline Behavioural problems & $188(11.9)$ & $46(3.3)$ & $3.6(2.6$ to 4.9$)$ & $<0.001$ \\
\hline
\end{tabular}

in each category of disability was calculated for the cohort as a whole and according to the organism involved and the age at infection.

\section{Results}

Altogether, 1717 children survived an acute attack of meningitis. Thirty three children could not be traced and 20 had emigrated, leaving 1664 possible participants. Altogether, 1539 of 1631 (94.3\%) general practitioners caring for children who had had meningitis and 1423 of $1543(92.2 \%)$ parents of these children responded to questionnaires. In the control group 1320 of $1485(88.8 \%)$ general practitioners and 1203 of $1400(85.9 \%)$ parents responded. Information was thus available from general practitioners or parents, or both, for 1584 (92.2\%) of children who survived an acute attack of meningitis and for 1391 of $1485(93.6 \%)$ controls.

\section{Deaths}

Of the 1717 children who survived the initial attack 32 later died. Two children who had otherwise been healthy died, one of septicaemic shock at age 4 years and the other of acute bronchiolitis at the age of 22 months. Sixteen children had had conditions consistent with the sequelae of meningitis. Fourteen had had conditions associated with extreme prematurity, congenital abnormalities (four had Down's syndrome), or non-related conditions such as lymphoblastic leukaemia. The cause of death was unknown for one child. An additional five children (one with Down's syndrome) were reported to have died at the time of the acute attack of meningitis.

\section{Health and development at five years}

The proportion of children with health and developmental problems is summarised in table 1 . The risk of problems was increased among children who had had meningitis, particularly the risk of having learning and neuromotor disabilities.

\section{Learning and neuromotor disabilities}

In 16 children learning difficulties were described as very severe; all of these children had had meningitis ( $1 \%$ of children in the meningitis group). Information on schooling was available for 90 children who had learning difficulties, and 70 were reported to have had special educational provision; 82 of the children with learning difficulties had had meningitis. Ten of the children who had had meningitis and who had learning difficulties also had congenital conditions associated with mental impairment: five had Down's syndrome, two had congenital mental impairment, two had dysmorphic features, and one had agenesis of the corpus callosum. Eighty four (5.3\%) children who had had meningitis had severe neuromotor disabilities compared with two $(0.1 \%)$ controls $\left(\chi^{2}=69.3, \mathrm{P}<0.001\right)$ (table 2). Cerebral palsy was the most common condition reported.

\section{Seizure disorders}

Regular anticonvulsant medication was taken by 53 $(45.7 \%)$ of the 116 children who had seizure disorders and had had meningitis; a further 24 had discontinued treatment. In contrast, only $5(13.5 \%)$ of the children 
Table 2 Number (percentage) of children with severe neuromotor disabilities at 5 years of age

\begin{tabular}{lcc} 
& \multicolumn{2}{c}{ Group } \\
\cline { 2 - 3 } Neuromotor disability & $\begin{array}{c}\text { Meningitis } \\
(\mathbf{n}=\mathbf{1 5 8 4})\end{array}$ & $\begin{array}{c}\text { Control } \\
(\mathbf{n}=\mathbf{1 3 9 1})\end{array}$ \\
\hline Cerebral palsy: & $79(4.9)$ & $2(0.1)$ \\
\hline Spastic hemiplegia & $28(1.7)$ & $1(0.1)$ \\
\hline Spastic quadriplegia & $10(0.6)$ & 0 \\
\hline Spastic diplegia & $8(0.5)$ & 0 \\
\hline Spastic paraplegia & $1(0.1)$ & 0 \\
\hline Monoplegia & $1(0.1)$ & 0 \\
\hline Double hemiparesis & $1(0.1)$ & 0 \\
\hline Ataxia & $6(0.4)$ & 0 \\
\hline Degree and type unspecified & $24(1.5)$ & $1(0.1)$ \\
\hline Other severe motor problems: & $5(3)$ & 0 \\
\hline Severe (unspecified) & $1(0.1)$ & 0 \\
\hline No voluntary movements & $1(0.1)$ & 0 \\
\hline Primitive reflexes only & $1(0.1)$ & 0 \\
\hline Multiple congenital malformations & $1(0.1)$ & 0 \\
\hline Bilateral amputations through knee & $1(0.1)$ & 0 \\
\hline Total & $84(5.3)$ & $2(0.1)$ \\
\hline
\end{tabular}

with seizure disorders in the control group regularly took anticonvulsant medication.

\section{Hearing impairment}

The overall relative risk of sensorineural hearing loss was 22.8 (95\% confidence interval 7.22 to 72.1$)$, with 90 $(5.6 \%)$ of the children who had had meningitis being affected; $29(1.8 \%)$ had a severe or profound bilateral loss. Three children in the control group $(0.2 \%)$ had mixed sensorineural-conductive loss. Middle ear problems were more prevalent among children who had had meningitis (272 children; $17.1 \%$ ) than among controls $(100$ children; 7.2\% $) \quad\left(\chi^{2}=67.22, \quad \mathrm{P}<0.001\right)$. However, 108 of 1399 (7.7\%) parents of children who had had meningitis and 144 of $1180(12.2 \%)$ parents of controls reported that their children's hearing had not been tested.

Visual and ocular problems

Six children were blind; they had all had meningitis. The most common condition reported was squint (116 children in the meningitis group $(7.3 \%) v 31$ controls $(2.2 \%))$. Parents reported that their children's vision had not been tested for 382 of 1414 (27\%) children who had had meningitis and 276 of 1200 (23\%) controls.

Speech and language problems

Fifty five children had severe communication problems or an absence of speech; all had had meningitis. A further 149 (9.4\%) children in the meningitis group and 53 in the control group (3.8\%) had speech or language delay, or both. In both groups children with speech and language problems also had hearing impairment, intellectual impairment, or both, (217/247 (87.6\%) children with meningitis $v 39 / 64(60.9 \%)$ controls).

\section{Behavioural problems}

Behavioural problems were more frequently described by parents than by general practitioners. The most common problems among children who had had meningitis were severe temper tantrums (44 children; $2.8 \%)$, hyperactivity $(17 ; 1.1 \%)$, and having poor concentration or being slow at school $(42 ; 2.6 \%)$.
Among the 32 children classed as having poor concentration or being slow at school there was no other apparent health problem. The behavioural problems reported for children in the control group were similar but less common. They included hyperactivity (10 children; $0.7 \%$ ), having poor concentration or being slow at school $(7 ; 0.5 \%)$, and having temper tantrums $(7 ; 0.5 \%)$; in four cases tantrums were described as severe $(0.3 \%)$.

\section{Categories of disability}

Table 3 classes the children by severity of disability. Children who had had meningitis had a 10-fold increase in the risk of having severe or moderate disabilities (relative risk 10.33, 95\% confidence interval 6.6 to $16.0, \mathrm{P}<0.001)$. Altogether, 617 of $1584(38.9 \%)$ affected children had multiple conditions. They also had an increased risk of mild disorders, such as middle ear disease, squint, and behavioural problems (relative risk 1.47, 95\% confidence interval 1.29 to 1.68 , $\mathrm{P}<0.001)$.

\section{Age at infection and organism of infection}

Children who were infected as neonates had more health and developmental problems than those who had meningitis when they were older than one month $\left(\chi^{2}=4.5, \mathrm{P}=0.03\right)$. In each area of health and development evaluated, prevalence rates for problems were higher for children who had had neonatal meningitis; this was particularly marked for neuromotor disabilities $(45 / 274(16.4 \%)$ who had neonatal meningitis $v$ $82 / 1304(6.3 \%)$ later meningitis, $\left.\chi^{2}=31.4, \mathrm{P}<0.001\right)$, seizure disorders $(33 / 274(12 \%)$ v $83 / 1304(6.4 \%)$, $\left.\chi^{2}=10.7, \mathrm{P}<0.01\right)$, and learning difficulties $(33 / 274$ $(12 \%) v 86 / 1304$ (6.6\%), $\chi^{2}=9.6, \mathrm{P}<0.01$ ) (data not shown). Although children with neonatal meningitis had an overall increase in the risk of having hearing problems, there was no significant difference in the prevalence of sensorineural hearing loss between the age groups. Children with neonatal meningitis were significantly more likely to have moderate disabilities $\left(\chi^{2}=72.2, \mathrm{P}<0.001\right)$, but the rate of severe disability was not significantly different between the groups (table 4). The rates of severe or moderate disability differed widely between children infected with different organisms (table 5). Although some of the differences may relate to the age at which the child contracted

Table 3 Number (percentage) of children by severity of disability at 5 years of age

\begin{tabular}{lcc} 
& \multicolumn{2}{c}{ Group } \\
\cline { 2 - 3 } & Meningitis ( $\mathbf{n = 1 5 8 4 )}$ & Control $(\mathbf{n = 1 3 9 1 )}$ \\
\hline Severe disability & $92(5.8)$ & $1(0.07)$ \\
\hline Moderate disability & $155(9.8)$ & $20(1.4)$ \\
\hline Mild disorder & $461(29.1)$ & $275(19.8)$ \\
\hline No disability & $876(55.3)$ & $1095(78.7)$ \\
\hline
\end{tabular}

Table 4 Number (percentage) of children with disability by time of infection

\begin{tabular}{lccc} 
& \multicolumn{3}{c}{ Time of infection } \\
\cline { 2 - 4 } & $\begin{array}{c}\text { Neonatal } \\
(\mathbf{n}=\mathbf{2 7 4})\end{array}$ & $\begin{array}{c}\text { Post-neonatal } \\
(\mathbf{n}=\mathbf{1 3 0 4})\end{array}$ & $\begin{array}{c}\text { Not known } \\
(\mathbf{n}=\mathbf{6})\end{array}$ \\
\hline Severe disability & $20(7.3)$ & $72(5.5)$ & 0 \\
\hline Moderate disability & $50(18.2)$ & $103(7.9)$ & $2(33)$ \\
\hline Mild disorder & $66(24.1)$ & $392(30.1)$ & $3(50)$ \\
\hline No disability & $138(50.4)$ & $737(56.5)$ & $1(16)$ \\
\hline
\end{tabular}




\begin{tabular}{|c|c|c|c|c|c|}
\hline Organism & $\begin{array}{l}\text { Severe } \\
\text { disability }\end{array}$ & $\begin{array}{l}\text { Moderate } \\
\text { disability }\end{array}$ & $\begin{array}{l}\text { Mild } \\
\text { disorder }\end{array}$ & $\begin{array}{c}\text { No } \\
\text { disability }\end{array}$ & Total \\
\hline Haemophilus influenzae & $14(3.4)$ & $30(7.3)$ & $134(32.5)$ & $235(57.0)$ & $413(26.0)$ \\
\hline Neisseria meningitidis & $12(2.9)$ & $26(6.5)$ & $120(29.8)$ & $244(60.7)$ & $402(25.4)$ \\
\hline Streptococcus pneumoniae & $14(9.7)$ & $20(13.9)$ & $37(25.8)$ & $72(50.3)$ & $143(9.0)$ \\
\hline Escherichia coli & $4(5.7)$ & $13(18.6)$ & $18(25.7)$ & $35(50.0)$ & $70(4.4)$ \\
\hline Group B streptococcus & $13(13.3)$ & $17(17.3)$ & $18(18.4)$ & $50(51.0)$ & $98(6.2)$ \\
\hline Echovirus & 0 & $2(6.4)$ & $11(35.5)$ & $18(58.0)$ & $31(1.9)$ \\
\hline Other virus & $4(21.1)$ & 0 & $4(21.1)$ & $11(57.9)$ & $19(1.2)$ \\
\hline Other Gram positive bacteria & $6(20.6)$ & $8(27.6)$ & $5(17.2)$ & $10(34.5)$ & $29(1.8)$ \\
\hline Other Gram negative bacteria & $8(25.0)$ & $10(31.3)$ & $7(21.9)$ & $7(21.9)$ & $32(2.0)$ \\
\hline Listeria monocytogenes & 0 & $4(25.0)$ & $3(18.8)$ & $9(56.3)$ & $16(1.0)$ \\
\hline Other micro-organisms & $2(28.6)$ & $4(57.1)$ & $1(14.3)$ & 0 & $7(0.4)$ \\
\hline No organism grown & $15(4.7)$ & $21(6.6)$ & $100(31.3)$ & $184(57.5)$ & $320(20.2)$ \\
\hline Not known & 0 & 0 & $3(75)$ & $1(25)$ & $4(0.2)$ \\
\hline Total & 92 & 155 & 461 & 876 & 1584 \\
\hline
\end{tabular}

meningitis, infection with certain organisms was consistently associated with a poorer long term prognosis.

Effects of gestational age and birth weight

Since prematurity and low birth weight are likely to have independent effects on outcome, the relative risk of severe or moderate disability when birth weight and gestational age were controlled for were calculated (tables 6 and 7). In these analyses children with pre-existing conditions, such as Down's syndrome or cerebral palsy, were excluded. A sevenfold increase in the risk of severe or moderate disability remained after birth weight and gestational age were controlled for.

\section{Discussion}

This study shows that meningitis in infancy has serious consequences. Two per cent of children who survived the acute attack died before the age of 5 years. Among the survivors there was a 10 -fold increase in the risk of severe or moderate disability compared with the control group. Neonatal meningitis was associated with a higher frequency of disability-especially neuromotor disabilities and seizure disorders-than meningitis after one month of age; however, there was no difference in the prevalence of sensorineural hearing loss between the groups. Infection with Streptococcus

Table 6 Number of children by birth weight and relative risk of severe or moderate disability* at age 5 years

\begin{tabular}{|c|c|c|c|}
\hline \multirow[b]{2}{*}{ Birth weight } & \multicolumn{2}{|c|}{ Severe or moderate disability } & \multirow[b]{2}{*}{$\begin{array}{c}\text { Relative risk } \\
(95 \% \mathrm{Cl})\end{array}$} \\
\hline & $\begin{array}{l}\text { Meningitis group } \\
\quad(n=1584)\end{array}$ & $\begin{array}{c}\text { Control group } \\
(n=1391)\end{array}$ & \\
\hline Very low birth weight $(<1500 \mathrm{~g})$ & $24 / 56$ & $0 / 8$ & Not calculable \\
\hline Low birth weight (1500-2500 g) & $29 / 149$ & $2 / 47$ & 4.57 (1.13 to 18.45$)$ \\
\hline Normal birth weight $(>2500 \mathrm{~g})$ & $113 / 1139$ & $15 / 1076$ & 7.22 (4.24 to 12.29) \\
\hline
\end{tabular}

*Mantel-Haenszel weighted relative risk $(95 \% \mathrm{Cl})$ for all $=7.11$ (4.30 to 11.73).

Table 7 Number of children by gestational age and relative risk of severe or moderate disability* at age 5 years

\begin{tabular}{lccc} 
& \multicolumn{2}{c}{ Severe or moderate disability } & \\
\cline { 2 - 3 } Gestational age & $\begin{array}{c}\text { Meningitis group } \\
(\mathbf{n = 1 5 8 4 )}\end{array}$ & $\begin{array}{c}\text { Control group } \\
\mathbf{( n = 1 3 9 1 )}\end{array}$ & $\begin{array}{c}\text { Relative risk } \\
\mathbf{( 9 5 \%} \mathbf{~ C l})\end{array}$ \\
\hline$<32$ weeks & $32 / 74$ & $0 / 11$ & Not calculable \\
\hline $32-36$ weeks & $30 / 170$ & $3 / 81$ & $4.76(1.50$ to 15.15$)$ \\
\hline$\geqslant 37$ weeks & $108 / 1092$ & $13 / 1037$ & $7.89(4.47$ to 13.94$)$ \\
\hline
\end{tabular}

pneumoniae was associated with a higher rate of disability than infection with Haemophilus influenzae and Neisseria meningitidis. This is consistent with the rates reported by Baraff et al and other prospective investigations, although their rates were not specific to infants. ${ }^{134}$ In this national cohort, severe disability was significantly more common in infants with meningitis associated with Group B streptococcus than with Escherichia coli. The highest rates of severe disability occurred among children whose meningitis was associated with Gram positive and Gram negative organisms classed as "other" (table 5). Our finding that $56 \%$ of infants with meningitis associated with Gram negative bacteria had severe or moderate disability is comparable with the $69 \%$ reported from a 20 year (1969-89) study in the United States. ${ }^{11}$

Although meningitis is more common during the first year of life than at any other age, it remains relatively uncommon. Because of the difficulty in finding adequate numbers of children in specific age groups for studies, reports of outcomes have relied on retrospective investigations, often done over many years, or on data from children referred to specialist centres, which by definition attract the more serious cases. As a result, there are few reliable estimates of the risk of long term disability associated with meningitis, particularly during the first year of life and during the neonatal period. ${ }^{2}$ The findings in this paper, based on follow up at five years of age of children enrolled in a national prospective study of meningitis in infancy, provide a complete picture of the range of problems experienced by children from England and Wales who have had meningitis in infancy. ${ }^{10}$

The objective of this study was to describe the effects of meningitis that could have an important impact on a child's life. However, subtle deficits, such as middle ear disease, squint, and behavioural problems, were also found to be more common among children who had had meningitis; this has been reported elsewhere. ${ }^{4}$ The higher rates of these conditions reported among the children who had had meningitis may reflect parental anxiety or the fact that closer attention is being paid to these children; thus, these higher rates need confirmation. This would require detailed investigation using standardised procedures to examine both children who have had and children who have not had meningitis. Although not as devastating as more disabling conditions, these are important problems that may adversely affect a child's wellbeing.

This study confirms the increased risk of hearing and visual problems among children who have had meningitis: many parents reported that their children's hearing and vision had not been tested. This lack of testing for hearing problems has been reported previously for children who have had meningitis. ${ }^{12-14}$ Units that treat children with meningitis should ensure that all survivors have their hearing and vision checked, even if they are asymptomatic.

The 1985 study found that $50 \%$ of neonates and $84 \%$ of infants were treated with chloramphenicol, usually in combination with either ampicillin or penicillin. ${ }^{10}$ Third generation cephalosporins were used to treat $46 \%$ of neonates but only $14 \%$ of post-neonatal infants. ${ }^{10}$ Treatment practice in the United Kingdom has changed since the earlier study: 


\section{What is already known on this topic}

Meningitis in infancy is associated with important long term consequences

There is considerable variation in outcome depending on which organism caused the infection

\section{What this study adds}

This follow up study of 1717 children who had meningitis in infancy found that they had a 10 -fold increase in risk of severe or moderate disabilities at age 5 years compared with children in the control group

The outcome of having meningitis was associated with the age at infection, and children who had meningitis in the neonatal period were more likely to have health and development problems than those older than 1 month

Subtle deficits, such as middle ear disease and visual and behavioural problems, were more prevalent among children who had had meningitis in infancy

the majority of neonates now receive third generation cephalosporins and few receive chloramphenicol. ${ }^{15}$

These findings not only provide information on the consequences of meningitis in infancy to assist health professionals in counselling parents but also provide background information for determining the effectiveness of new treatments and the need for preventive measures.

We thank the parents and general practitioners who completed the questionnaires and the paediatricians for assisting in the fol- low up of the children. We thank David Dunn for statistical advice and Janet Masters for assistance in coding and entering the data.

Contributors: DH, JdeL, CP, and RH had the idea for the study. HB and SH managed the study and coded and entered the data. $\mathrm{HB}$ was responsible for analysing the data and drafting the paper. All authors participated in designing the study, applying for the grant, and revising the paper. $\mathrm{DH}$ and $\mathrm{CP}$ are the guarantors for the paper.

Funding: Action Research and the Fayed Charitable Foundation.

Competing interests: None declared.

1 Baraff LJ, Lee SI, Schriger DL. Outcomes for bacterial meningitis in children: a meta-analysis. Pediatr Infect Dis 1993;12:389-94.

2 Davies PA, Rudd PT. Neonatal meningitis. London: MacKeith Press, 1994:140-5.

3 McIntyre P, Jepson R, Leeder S, Irwig, L. The outcome of childhood Haemophilus influenzae meningitis. Med J Aust 1993;159:766-72.

4 Grimwood K, Anderson VA, Bond L, Catroppa C, Hore RL, Keir EH, et al. Adverse outcomes of bacterial meningitis in school-age survivors. Pediatrics 1995;95:646-56.

5 Feldman HM, Michaels RH. Academic achievement in children ten to 12 years after Haemophilus influenzae meningitis. Pediatrics 1988;81:33944.

6 Berlow SJ, Caldarelli DD, Matz GJ, Meyer DH, Harsch GG. Bacterial meningitis and sensorineural hearing loss: a prospective investigation. Laryngoscope 1980;90:1445-52.

7 Dodge PR, Davis H, Feigin RD, Holmes SJ, Kaplan SL, Jubelirer DP, et al Prospective evaluation of hearing impairment as a sequela of acute bacterial meningitis. N Engl J Med 1984;311:869-74.

8 Kaplan SL, Goddard J, Van Kleeck M, Catlin FI, Feigin RD. Ataxia and deafness in children due to bacterial meningitis. Pediatrics 1981;68:8-13.

9 Nadol JB. Hearing loss as a sequela of meningitis. Laryngoscope 1978;88:739-55.

10 De Louvois J, Blackbourn J, Hurley R, Harvey D. Infantile meningitis in England and Wales: a two year study. Arch Dis Child 1991;66:603-7.

11 Unhanand M, Mustafa MM, McCracken GH Jr, Nelson JD. Gram-negative enteric bacillary meningitis: a twenty-one-year experience. I Pediatr 1993;122:15-21.

12 Riordan A, Thomson A, Hodgson J, Hart A. Children who are seen but not referred: hearing assessment after bacterial meningitis. $\mathrm{Br} J$ Audio 1993;27:375-7.

13 Fortnum HM, Hull D. Is hearing assessed after bacterial meningitis? Arch Dis Child 1992;67:1111-2.

14 Shields MD, Adams D, Beresford P, Dodge JA. Managing meningitis in children: audit of notifications, rifampicin chemoprophylaxis, and audiological referrals. Qual Health Care 1995;4:269-72.

15 Holt DE, Halket S, de Louvois J, Harvey D. Neonatal meningitis in England and Wales. Arch Dis Child Fetal Neonatal Ed 2001;84:F85-9.

(Accepted 8 March 2001) 